\title{
Simultaneous transport of water and solutes under transient unsaturated flow conditions - A case study
}

\author{
B K Purandara*, N Varadarajan and B Venkatesh \\ National Institute of Hydrology, Hard Rock Regional Center, Belgaum 590 001, Karnataka, India. \\ *e-mail: purandarabk@yahoo.com
}

\begin{abstract}
The imbalance between incoming and outgoing salt causes salinization of soils and sub-soils that result in increasing the salinity of stream-flows and agriculture land. This salinization is a serious environmental hazard particularly in semi-arid and arid lands. In order to estimate the magnitude of the hazard posed by salinity, it is important to understand and identify the processes that control salt movement from the soil surface through the root zone to the ground water and stream flows. In the present study, Malaprabha sub-basin (up to dam site) has been selected which has two distinct climatic zones, sub-humid (upstream of Khanapur) and semi-arid region (downstream of Khanapur). In the upstream, both surface and ground waters are used for irrigation, whereas in the downstream mostly groundwater is used. Both soils and ground waters are more saline in downstream parts of the study area. In this study we characterized the soil salinity and groundwater quality in both areas. An attempt is also made to model the distribution of potassium concentration in the soil profile in response to varying irrigation conditions using the SWIM (Soil-Water Infiltration and Movement) model. Fair agreement was obtained between predicted and measured results indicating the applicability of the model.
\end{abstract}

\section{Introduction}

In arid and semi-arid regions the imbalance between incoming and outgoing salt has resulted in accumulation of salts in the irrigated soils. Since, the salt tolerance of crops is often based on the concentration of salts in the saturated extracts; it would be useful to have a method to predict the salt concentration throughout the soil profile under field conditions. In order to estimate the magnitude of the hazard posed by salinity, it is important to understand and identify the processes that control salt movement from the soil surface through the root zone to the ground waters and stream flows.

The transport of reactive chemicals in porous media undergoes various chemical changes through advection, diffusion and dispersion. In addition, it involves other mechanisms like rate-limited sorption and desorption, biodegradation, and chemical reaction. To understand the process of transport of chemicals through soil layers and porous media, several mathematical models have been developed (Valocchi 1985; Evans and Stagnitti 1996; Srivastava and Brusseau 1996; Xu and Brusseau 1996; Stagnitti and Li 1999, 2001; De Rooij and Stagnitti 2000; Rajmohan and Elango 2001).

The impact of agricultural activities on ground water quality is closely related with the quality of water from precipitation and irrigation water. SoilWater systems in the unsaturated zone are highly complex. Firstly, it is seldom in stable equilibrium and is in constant flux. The degree of saturation of soil-water $(\theta)$ varies both in time and space. This in turn affects flow parameters namely the suction head $h(\theta)$ and the hydraulic conductivity $K(\theta)$ which are not unique functions of $\theta$, but exhibits hysterises. In addition, there is the effect of airflow through the soil and the compressibility of air, which may have some effect on unsaturated flow,

Keywords. Hydraulic conductivity; infiltration; leaching; Malaprabha; modeling; permeability; salinity; solute transport; SWIM model; water flow. 


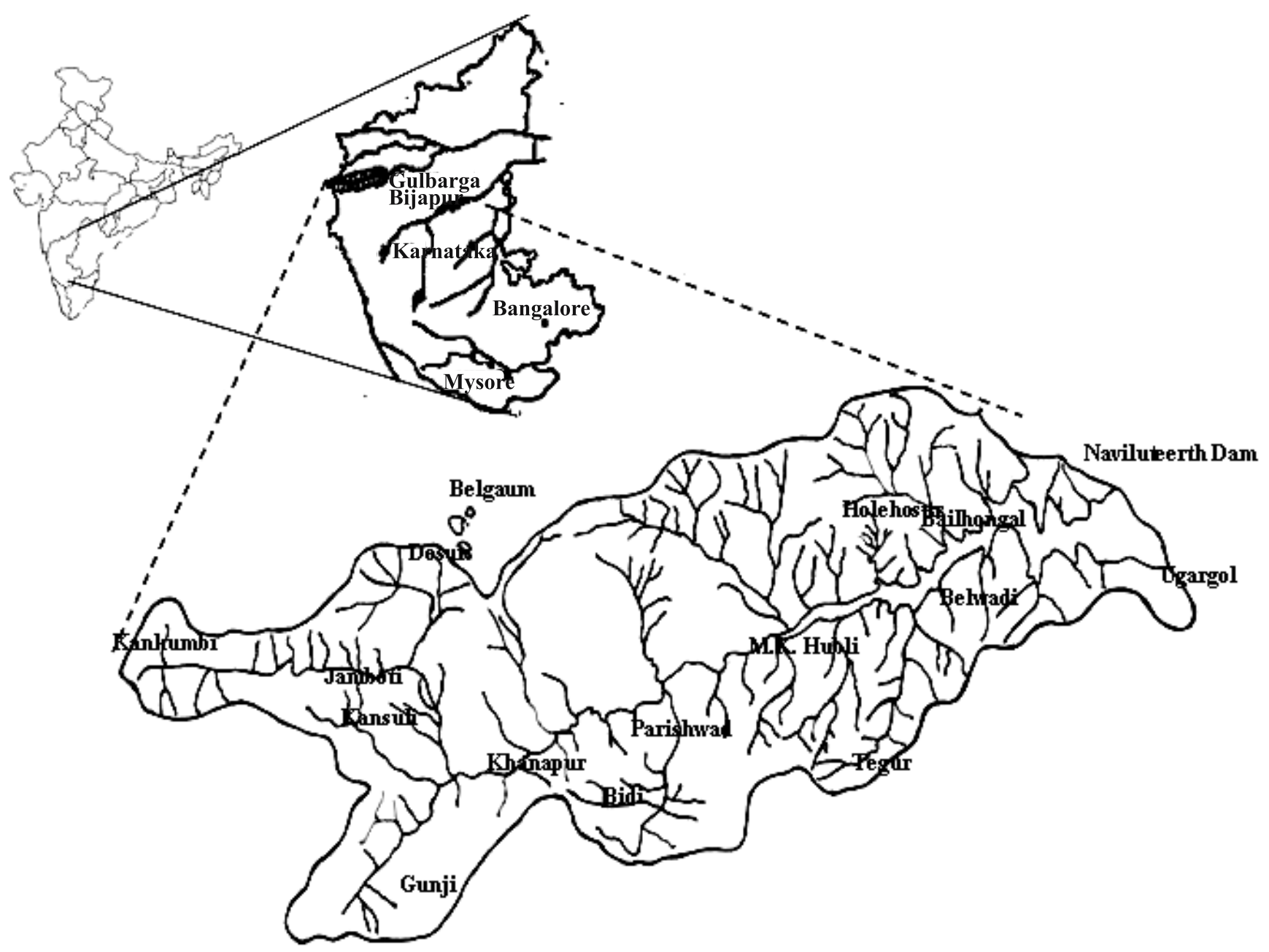

Figure 1. Index map of the study area (Malaprabha sub-basin) with groundwater sampling locations.

and in few cases, the soil may undergo chemical changes. Water quality problems of all kinds stem from the lack of awareness of these processes. Fertilizers are applied to agricultural fields to increase the crop yields. However, a part of the chemical constituents present in the fertilizer may percolate down to reach the ground water table thereby polluting the fresh water aquifers. It is therefore important to limit the application of fertilizers and monitor their movement in the unsaturated zone. In the present study, the solute transport process in two agricultural zones representing sub-humid (Khanapur) and semi-arid (Bailahongal) conditions in Malaprabha sub-basin has been modeled using the SWIM (Soil-Water-InfiltrationMovement) model. Saturated hydraulic conductivity was measured in the field using Guelph permeameter and soil sampling was done before and after application of fertilizer (N-P-K). Soil moisture retention characteristics were obtained in the laboratory using the Pressure Plate Apparatus.

\section{Study area}

The Malaprabha river is a right bank tributary of river Krishna. It extends between $74^{\circ} 20^{\prime}$ and $75^{\circ} \mathrm{E}$ longitude and $15^{\circ} 20^{\prime}$ and $15^{\circ} 40^{\prime} \mathrm{N}$ latitude in Belgaum district of Karnataka (figure 1). To harness the waters of the Malaprabha river, a dam has been constructed at Naviluteerth, Belgaum district to impound $1377 \mathrm{MCM}$ water. There are three seasons prevailing in the catchment, the summer from March to May, the monsoon from June to November and the winter from December to February. The Malaprabha catchment has two distinct rainfall regimes, i.e., the area upstream of Khanapur has an annual average rainfall of $2000 \mathrm{~mm}$, whereas the downstream of Khanapur, the average rainfall is about $600 \mathrm{~mm}$. However, the average annual rainfall in the catchment is $800 \mathrm{~mm}$.

Geologically, the area comprises of sedimentary rock formations (Kaladgi group, comprising limestone, shale and quartzites) and schistose 
rock formations (Dharwad Super group comprising granite, gneiss and crystalline rocks). The important soil groups found in the catchment include medium-to-deep black soil, mixed red and black soil (Vertisols) and red sandy loam soils (mainly Alfisols).

The land use pattern of Malaprabha sub-basin shows that $25.35 \%$ is covered by forests, $10.52 \%$ shrub, $7.85 \%$ waste land, $33.08 \%$ cropped area, $19.23 \%$ fallow land and remaining $3.97 \%$ is occupied by water bodies.

\section{Materials and methods}

Ground water samples were collected from selected wells (locations are shown in figure 1) during premonsoon and post-monsoon seasons and analysed for various chemical parameters such as, electrical conductivity (EC), total alkalinity $\left(\mathrm{CO}_{3} \& \mathrm{HCO}_{3}\right)$, total dissolved solids (TDS), chloride $(\mathrm{Cl})$, sulphate $\left(\mathrm{SO}_{4}\right)$, sodium $(\mathrm{Na})$, potassium $(\mathrm{K})$, calcium $(\mathrm{Ca})$ and magnesium $(\mathrm{Mg})$ which were determined in water. $\mathrm{pH}, \mathrm{EC}$, and TDS were determined by using electrometric method. Total alkalinity, $\mathrm{Ca}$, and $\mathrm{Mg}$ were estimated by using titration method (titration with EDTA). Chloride is estimated volumetrically by Mohr's method, titrating against standard silver nitrate solution in the presence of potassium chromate indicator. Sulphate is determined by turbidimetric method using photoelectric colorimeter. Na and $\mathrm{K}$ concentration is determined by using Flame photometer. Soil samples were collected from agriculture fields located at Khanapur (red soil) and also from Bailahongal (medium-deep black soil). In the case of soil samples, soil extracts were prepared and analysed for chemical parameters by standard methods (Black 1965). pH of the soil was determined by weighing $20 \mathrm{~g}$ of air-dry soil into a beaker, and $50 \mathrm{ml}$ distilled water was added and stirred at regular intervals for about an hour. Then $\mathrm{pH}$ is measured using $\mathrm{pH}$ meter. The electrical conductivity was measured by conductivity meter.

The cation exchange capacity of a soil is the total negative charge of the soil measured under specific conditions. Its determination involves the saturation or all the charges by one cation. Conventionally, for soils with less than 7.0, Ammonium $\left(\mathrm{NH}_{4}\right)$ is the cation of choice, and the determination is done at $\mathrm{pH} 7.0$ by leaching the soil with $\mathrm{NH}_{4} \mathrm{OAc}$ solution buffered at that $\mathrm{pH}$. Kjeldahl distillation apparatus was used for the estimation of calcium and magnesium. Sodium and potassium were determined by analyzing the ammonium acetate extract directly for sodium and potassium using Flame photometer.

\subsection{Estimation of soil hydraulic properties}

Saturated hydraulic conductivity was determined by using disc permeameter and Guelph permeameter. Saturated moisture content was estimated by gravimetric method and soil moisture retention characteristics were determined by using pressure plate apparatus. Detailed methodology is given below.

\subsubsection{Disc permeameter}

The disc permeameter (Perroux and White 1988) was used for the determination of soil hydraulic conductivity at the surface. The instrument allows a constant supply potential, either positive or negative, in a manner analogous to ponded ring devices. Based on the expression developed by Wooding (1968), for three dimensional flow from a circular disc, the steady state infiltration $\left(q_{\infty}\right)$ is expressed as:

$$
q_{\infty}=K^{*}+\frac{4 b\left(S_{0}\right)^{2}}{\left(\theta_{0}-\theta_{n}\right) \pi r}
$$

(where $b$ is a constant and taken as 0.55), $\theta_{0}$ is the saturated moisture content and $\theta_{n}$ is the in situ moisture content, $r$ is the radius of the disc $(0.1 \mathrm{~m})$. When the disc permeameter test is run, data are collected to obtain cumulative infiltration at various times after the start of the test. $S_{0}$ can be found from the slope of early-time plot of $q_{\infty}$ vs. $S t^{1 / 2}$ and $q_{\infty}$ from the slope of the late time plot of $q_{\infty}$ vs. $t$. The water content is measured before and after the experiment (by taking soil samples for gravimetric water content multiplied by dried bulk density determinations) to obtain the saturated moisture content $\left(\theta_{0}\right)$ and in situ moisture content $\left(\theta_{n}\right)$. Thus $K$ can then be calculated from equation (1).

The disc permeameter is a portable equipment, which can be used for the measurement of infiltration, hydraulic conductivity and pore characteristics, although only the hydraulic conductivity is reported here.

\subsubsection{Guelph permeameter}

The Guelph permeameter (Reynold et al 1985) was used to determine the depth-wise field saturated hydraulic conductivity. The method involves measuring the steady state rate of water recharge into unsaturated soil from a cylindrical well hole, in which a constant depth (head) of water is maintained. Constant head level in the well hole is established and maintained by regulating the level of the bottom of the air tube which is located in 
the centre of the permeameter. As the water level in the reservoir falls, a vacuum is created in the air space above the water. The vacuum can only be relieved when air, which enters at the top of the air tube, bubbles out of the air inlet tip and rises to the top of the reservoir. Whenever the water level in the well begins to drop below the air inlet tip, air bubbles emerge from the tip and rise into reservoir air space. The vacuum is then partially relieved and water from the reservoir replenishes the water in the well. The size of opening and geometry of the air inlet tip is designed to control the size of air bubbles in order to prevent the well water level from fluctuating.

The steady state discharge from a cylindrical well in unsaturated soil, as measured by the Guelph permeameter technique accounts for all the forces that contribute to three dimensional flow of water into soils, the hydraulic push of water into soil, the gravitational pull of liquid out through bottom of the well, and the capillary pull of water out of the well into the surrounding soil. The Richard analysis is the basis for the calculation of field saturated hydraulic conductivity. The following formulae are used to determine field saturated hydraulic conductivity, $K_{\mathrm{fs}}$ and matric flux potential, $\phi_{\mathrm{m}}$ when following the standardized procedure

$$
\begin{gathered}
K_{\mathrm{fs}}=(0.0041)(X)\left(R_{2}\right)-(0.0054)(X)\left(R_{1}\right), \\
\phi_{\mathrm{m}}=(0.0572)(X)\left(R_{1}\right)-(0.0237)(X)\left(R_{2}\right),
\end{gathered}
$$

where,

$$
\begin{aligned}
& X= \text { Reservoir constant used when the combined } \\
& \text { reservoir of the equipment is used; } \\
& R_{1}= \text { Steady state rate of fall of water in the } \\
& \text { reservoir at first well height (always } 5 \mathrm{~cm} \text { in } \\
& \text { the standardized procedure); } \\
& R_{2}=\begin{array}{l}
\text { Steady state rate of fall of water in the } \\
\text { reservoir at second well height }(10 \mathrm{~cm} \text { in the } \\
\text { standard procedure). }
\end{array}
\end{aligned}
$$

\subsubsection{Soil moisture retention curves}

The graph between soil moisture tension and soil moisture content is referred to as soil moisture retention curve or soil moisture characteristic. If the tension is expressed as the logarithmic value of $\mathrm{cm}$ water, the graph is represented as $\mathrm{pF}$-curve. To construct the moisture retention curve of a soil sample, the moisture content of the sample must be measured. This is done by equilibrating the moist soil sample at a succession of known $\mathrm{pF}$ values and each time determining the amount of moisture that is retained. If the equilibrium moisture content (expressed preferably as volume percentage) is plotted against the corresponding tension $(\mathrm{pF})$, the moisture retention curve ( $\mathrm{pF}$-curve) can be drawn. The pressure plate apparatus is used for the determination of $\mathrm{pF}$ curves in the $\mathrm{pF}$ range of 2.0 to 4.2 (0.1-15 bar of suction). Soil moisture is removed from the soil samples by raising air pressure in an extractor. A porous ceramic plate serves as a hydraulic link for water to move from the soil to the exterior of the extractor. The high pressure air will not flow through the pores in the plate since the pores are filled with water. The smaller the pore size, the higher the pressure that can be exerted before air passes through. During an experimental run, at any set pressure in the extractor, soil moisture will flow around each of the soil particles and out through the ceramic plate and outflow tube. Equilibrium is reached when water flow from the outflow tube ceases. At equilibrium, there is an exact relationship between the air pressure in the extractor and the soil suction (and hence the moisture content) in the samples. Accuracy of equilibrium values will be no more accurate than the regulation of air supply; therefore, the pressure control panel has independent double regulators. For each soil type, the characteristic $\mathrm{pF}$-curve may be developed. These curves relate the soil suction to its moisture content. The relationship is important in the study of soil moisture movement and quantity and availability of soil moisture for plant growth.

\section{Soil Water Infiltration and Movement (SWIM) model}

SWIMv2.1 is based on a numerical solution of the Richards equation and the advection-dispersion equation. In the present study, the model has been applied to simulate the movement of solute in the unsaturated zone. The physical system and the associated flows addressed by the model are shown schematically in figure 2. Soil water and solute transport properties, initial conditions, and time dependent boundary conditions (e.g., precipitation, evaporative demand, solute input) were supplied in order to run the model (Verburg et al 1996). The governing partial differential equation (Richards equation) applicable for one-dimensional flow in the unsaturated zone can be written as:

$$
\frac{\partial \theta}{\partial t}=\frac{\partial}{\partial x} K\left[\frac{\partial \psi}{\partial x}+\frac{d z}{d x}\right]+S,
$$




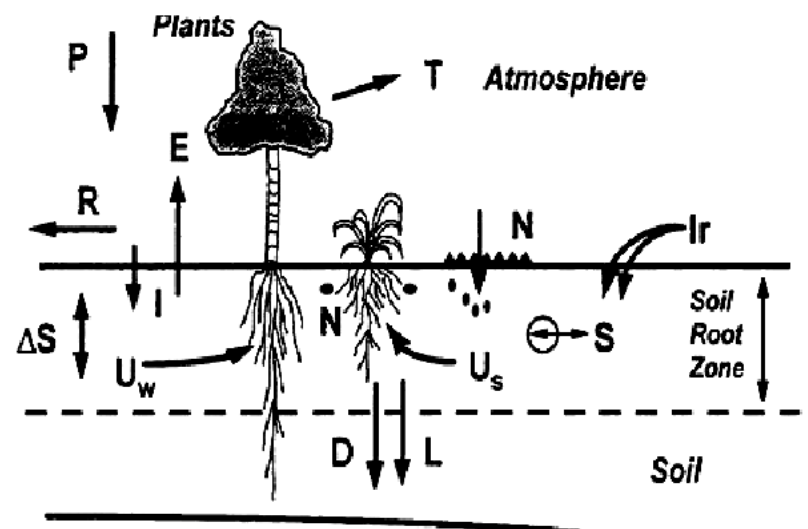

Groundwater

Components of the soil water and solute balances addressed by SWIMv2.1; $\mathrm{P}=$ Precipitation, $\mathrm{R}=\mathrm{Runoff}, \mathrm{I}=$ Ifilitration, $\mathrm{U}_{w}=$ Water uptake, Us = Solute uptake, $\mathrm{T}=$ Transpiration, $\mathrm{E}=$ Evaporation, $\mathrm{D}=$ Drainage, $\mathrm{L}=$ Solute leaching,

$\mathrm{I}_{\mathrm{t}}=$ Irrigation/Fertigation, $\mathrm{N}=$ Nutrients/Fertiliser, $\Delta \mathrm{S}=$ Storage,

$S=$ Solute source/Sink (after Verburg et al 1996)

Figure 2. Schematic representation of SWIMv2.1 model with components of soil water and solute balances.

where,

$\theta=$ volumetric water content $\left(\mathrm{cm}^{3} / \mathrm{cm}^{3}\right)$

$t=$ time $(\mathrm{h})$

$x=$ distance into the soil (cm soil)

$K=$ hydraulic conductivity $\left(\mathrm{cm}^{2}\right.$ water $/ \mathrm{cm}$ soil/h)

$\Psi=$ matric potential (cm water)

$z=$ gravitational potential $(\mathrm{cm})$; and

$S=$ sink strength $\left(\mathrm{cm}^{3}\right.$ water $/ \mathrm{cm}^{3}$ soil $\left./ \mathrm{h}\right)$

where $\theta$ and $\Psi$ related by the water retention curve and $K$ is related to $\theta$ by the hydraulic conductivity function. This so-called mixed $\theta$ and $\Psi$ form of the Richard's equation is solved numerically with the Newton-Raphson iterative method (Campbell 1985). For the purpose of numerically solving the equation (4), the soil profile is represented by a series of nodes (depth-wise); the number and spacing (for example, $10 \mathrm{~cm}, 20 \mathrm{~cm}, \ldots$ ) of which are determined by the user in the input file. Smaller depth increments lead to more accurate solutions (Ross and Bristow 1990). The first node defined by the user is always taken as the soil surface or top boundary. Therefore, the equation (4) can then be discretised on a space-time grid.

Solute transport phenomena are explained by the equation given below:

$$
\frac{\partial(\theta c)}{\partial t}+\frac{\partial(\rho s)}{\partial t}=\frac{\partial}{\partial x}\left[\theta D \frac{\partial c}{\partial x}\right]-\frac{\partial(q c)}{\partial x}+\phi,
$$

where,

$c=$ solute concentration in solution ( $\mu$ mol or $\mu \mathrm{g}$ solutes $/ \mathrm{cm}^{3}$ water)

$$
\begin{aligned}
s= & \text { adsorbed concentration }(\mu \mathrm{mol} / \mathrm{g} \text { soil or } \\
& \mu \mathrm{g} / \mathrm{g} \text { soil }) \\
\rho= & \text { soil bulk density }\left(\mathrm{g} / \mathrm{cm}^{3}\right) \\
q= & \text { water flux density }(\mathrm{cm} / \mathrm{h}) \\
D= & \text { combined dispersion and diffusion coeffi- } \\
& \text { cient }\left(\mathrm{cm}^{2} / \mathrm{h}\right) \\
\phi= & \text { source } / \mathrm{sink} \text { term }\left(\mu \mathrm{mol} / \mathrm{cm}^{3} / \mathrm{h}\right. \text { or } \\
& \left.\mu \mathrm{g} / \mathrm{cm}^{3} / \mathrm{h}\right) .
\end{aligned}
$$

\section{Model conceptualization}

The SWIM model was applied to Malaprabha sub-basin to understand the solute transport characteristics that pass through the unsaturated zone. This solute will enter the soil profile with the irrigation. Rawat et al (1993) reported two distinct layers of soil in the study area. Therefore, to account for the spatial variation of saturated hydraulic conductivity, twelve in situ field experiments were conducted on the soil surface (top layer) and also at the bottom layer $(45-60 \mathrm{~cm}$ depth) at different locations with different soil types. Logarithmic mean value was considered as the model input parameter. The model was run under two conditions, one in the red soil area (Khanapur) with single vegetation (Jowar) and the second run is for the downstream area, dominated by medium to black soil (Bailahongal), where Gram is the type of vegetation. Solute is included in the simulation through application of fertilizer $(\mathrm{N}-\mathrm{P}-\mathrm{K})$ at the surface. The model was simulated for 30 days comprising two irrigations of $6 \mathrm{~cm}$ each on 3- and 20-day and one application of fertilizer (solute). Exponential root growth with depth and linear interpolation with time was considered. The profile is $150 \mathrm{~cm}$ deep with surface at $0 \mathrm{~cm}$ and bottom boundary condition applying at $150 \mathrm{~cm}$. There is also some solute present initially. Solute production and first order decay processes are active. In the model, solute production/uptake and first order decay processes are expressed in terms of source or sink terms. There is no solute exclusion from plant water uptake, i.e., all solute dissolved in the uptake water is also taken up by the plant. Plant uptake of solute is assumed to take place only by mass flow. In this case, vapour conductivity is not taken into account nor is the effect of osmotic potential. There are two hydraulic property sets (for upper and lower soil layers) that are applied at 16 depth nodes of the $150 \mathrm{~cm}$ deep profile. Initially, there is no water ponded on the surface. Runoff is governed by simple power law function. A matric potential gradient of 0, i.e., 'unit gradient', has been applied as bottom boundary condition throughout the simulation. Runoff in SWIMv2.1 is based on the assumption that the soil 
has a certain surface roughness, which can detain water and prevent it from running off.

\subsection{Data acquisition}

Rainfall: Daily rainfall data for the period 1984-2005 were collected from the statistical department (Karnataka State) for rain gauges located within the catchment of Malaprabha subbasin.

Evaporation: Daily evaporation data of Khanapur and Naviluteerth dam site (1984-1993) were obtained from the Karnataka State Irrigation Department.

Saturated hydraulic conductivity: Saturated hydraulic conductivity was measured at 12 stations using disc permeameter and Guelph permeameter. The saturated hydraulic conductivity near Khanapur is taken as $2.1 \mathrm{~cm} / \mathrm{h}$ (surface) and at a depth of $45 \mathrm{~cm}$ to $60 \mathrm{~cm}$, it is $0.9 \mathrm{~cm} / \mathrm{h}$. In areas, dominated by black soils, the values considered are $0.6 \mathrm{~cm} / \mathrm{h}$ at the surface and $0.01 \mathrm{~cm} / \mathrm{h}$ at the bottom layer.

Van Genuchten parameters: Soil samples were analyzed in the laboratory for soil moisture retention characteristics by using pressure plate apparatus. The averaged van Genuchten parameters for the soil layer were obtained by non-linear regression analysis. The van Genuchten parameter $\alpha_{v}$ varies between $0.0083 \mathrm{~cm}^{-1}$ and $0.0560 \mathrm{~cm}^{-1}$ and the $n$ parameter varies between 1.4046 and 1.5037 .

Vegetation: Two types of vegetation (Jowar/Gram) showing exponential root growth with depth and sigmoid with time were assumed for the study. Data pertaining to vegetation type was not available; therefore, it is adopted from the study carried out by Kumar \& Shilpa (2002) for the NargundNavalgund area in Dharwad district.

\section{Jowar}

Root radius (rad)

$=0.08 \mathrm{~cm}$

Root conductance (groot) $\quad=1.2 * 10^{-7}$

Minimum xylem potential (psimin) $=-15000 \mathrm{~cm}$

Root depth constant (xc) $\quad=30 \mathrm{~cm}$

Maximum root length density $\quad=4 \mathrm{~cm} / \mathrm{cm}^{3}$

(rldmax)

\section{Grams}

Root radius (rad)

$=0.12 \mathrm{~cm}$

Root conductance (groot) $\quad=1.0 * 10^{-7}$

Minimum xylem potential $($ psimin $)=-15000 \mathrm{~cm}$
Root depth constant (xc)

Maximum root length density $(\operatorname{rldmax})$

$=20 \mathrm{~cm}$

$=3 \mathrm{~cm} / \mathrm{cm}^{3}$

\section{Results and discussion}

\subsection{Soil salinity}

Soil salinization has been observed in the downstream part of the Malaprabha sub-basin. Presently, it is noticed that only about 15-20\% of the study area (out of the total irrigated land) are salt affected (i.e., ECe $>4 \mathrm{ds} / \mathrm{m}$ ). Although soil salinity was generally low, it tended to increase with depth, due to the accumulation of salt in the deeper layer which could be attributed to the presence of higher clay content and low permeability as observed in the soil profile. Thus, the percentage of the irrigated area with ECe values higher than $4 \mathrm{ds} / \mathrm{m}$ was $6.8 \%$ for the $0-30 \mathrm{~cm}$ soil depth and increased to $15.7 \%$ for the $60-90 \mathrm{~cm}$ soil depth. The ECe values being greater than $4 \mathrm{ds} / \mathrm{m}$ in the soil horizons of downstream region indicate a high level of salinity particularly in deep to medium black soils (typic chromusterts and vertic ustropepts) of Bailahongal taluk. Calcium is the dominant base on exchange complex with $\mathrm{Ca} / \mathrm{Mg}$ ranging from 3.2 to 3.6 for black soils and for red soil it varies between 1.83 and 3.57. It is observed that in a mixed cation system where both $\mathrm{Na}$ and $\mathrm{Ca}$ are present on clay, the ratio of $\mathrm{Na}$ to $\mathrm{Ca}$ in soil solution affects the ratio of Ex $\mathrm{Na}$ and Ex Ca. Further, small changes in ESP result in large increase in SAR values and the proportion of $\mathrm{Na}$ in soil solution (Bhaskar et al 1998).

\subsection{Hydrochemistry of anions and cations}

Acid-base reactions are important in groundwater because of their influence on $\mathrm{pH}$ and the ion chemistry. A pH value of 7.5 to 8.0 usually indicates the presence of carbonates of calcium and magnesium, and a $\mathrm{pH}$ of 8.5 or above shows appreciable exchangeable sodium. The results of the present study (table 1) show clearly the dominance of bicarbonate, sodium and chloride towards downstream as compared to upstream.

The total concentration of soluble salts expressed as electrical conductivity in ground water of Malaprabha sub-basin varied from 0.36 to $29.6 \mathrm{ds} / \mathrm{m}$. However, it is observed that in most of the cases $(42 \%)$, the EC was more than $4 \mathrm{ds} / \mathrm{m}$, and $28 \%$ samples had EC less than $2.5 \mathrm{ds} / \mathrm{m}$, thereby indicating that salinity is more prevalent than sodicity in the study area. Studies carried out by Jain et al (2001) also reported a similar 
Table 1. Measured chemical properties of the water samples collected from open well (OW) and bore well (BW) during pre-monsoon (*) and post-monsoon (**) (unit; mg/l).

\begin{tabular}{|c|c|c|c|c|c|c|c|c|c|c|c|c|}
\hline Stations & $\mathrm{pH}$ & $\begin{array}{c}\mathrm{EC} \\
\mu \mathrm{mhos} / \\
\mathrm{cm}\end{array}$ & TDS & $\mathrm{CO}_{3}$ & $\mathrm{HCO}_{3}$ & $\mathrm{Cl}$ & $\mathrm{SO}_{4}$ & $\begin{array}{c}\text { Hardness } \\
\text { as } \mathrm{CaCO}_{3}\end{array}$ & $\mathrm{Ca}$ & $\mathrm{Mg}$ & $\mathrm{Na}$ & K \\
\hline \multicolumn{13}{|c|}{ Kankumbi (BW) } \\
\hline$*$ & 7.00 & 59.90 & 36.00 & NIL & 63.68 & 7.10 & 50.00 & 10.00 & 3.20 & 0.50 & 3.90 & 1.00 \\
\hline$* *$ & 8.10 & 184.80 & 111.00 & NIL & 134.40 & 12.40 & 295.0 & 154.0 & 25.60 & 22.0 & 3.40 & 0.40 \\
\hline \multicolumn{13}{|c|}{ Kankumbi (OW) } \\
\hline$*$ & 9.40 & 148.30 & 89.00 & NIL & 84.90 & 8.86 & 52.00 & 28.00 & 7.20 & 2.44 & 5.25 & 1.40 \\
\hline$* *$ & 5.90 & 36.10 & 21.60 & NIL & 35.38 & 7.10 & 48.00 & 20.00 & 2.40 & 3.42 & 4.80 & 1.00 \\
\hline \multicolumn{13}{|c|}{ Jamboti (OW) } \\
\hline$*$ & 8.40 & 204.00 & 122.60 & NIL & 77.84 & 17.72 & 57.00 & 40.00 & 9.60 & 3.90 & 6.90 & 8.40 \\
\hline$* *$ & 6.70 & 326.00 & 195.50 & NIL & 169.82 & 12.40 & 73.50 & 82.00 & 17.60 & 9.27 & 18.00 & 7.45 \\
\hline \multicolumn{13}{|c|}{ Jamboti (BW) } \\
\hline$*$ & 8.05 & 398.00 & 239.00 & NIL & 290.10 & 7.10 & 92.50 & 94.00 & 28.80 & 5.37 & 29.50 & 2.70 \\
\hline$* *$ & 7.50 & 454.00 & 272.00 & NIL & 297.20 & 8.86 & 92.50 & 110.00 & 28.80 & 9.27 & 48.00 & 7.45 \\
\hline \multicolumn{13}{|c|}{ Jamboti (BW) } \\
\hline$*$ & 8.30 & 200.00 & 120.20 & NIL & 77.84 & 10.64 & 80.50 & 50.00 & 11.20 & 5.37 & 5.50 & 0.60 \\
\hline$* *$ & 7.10 & 146.30 & 87.80 & NIL & 84.90 & 12.40 & 71.00 & 44.00 & 7.20 & 6.34 & 20.00 & 1.20 \\
\hline \multicolumn{13}{|c|}{ Kansuli (BW) } \\
\hline$*$ & 8.70 & 270.00 & 161.90 & NIL & 198.13 & 28.36 & 78.00 & 60.00 & 12.80 & 6.83 & 15.50 & 3.25 \\
\hline$* *$ & 8.20 & 313.00 & 187.60 & NIL & 212.30 & 12.40 & 85.00 & 90.00 & 23.20 & 7.80 & 9.00 & 1.75 \\
\hline \multicolumn{13}{|c|}{ Khanapur (OW) } \\
\hline$*$ & 8.60 & 394.00 & 237.00 & NIL & 106.14 & 46.10 & 113.50 & 46.00 & 12.80 & 3.42 & 25.00 & 36.50 \\
\hline$* *$ & 7.60 & 608.00 & 366.00 & NIL & 92.00 & 90.40 & 100.00 & 76.00 & 16.00 & 8.80 & 25.00 & 31.00 \\
\hline \multicolumn{13}{|c|}{ Gunji (OW) } \\
\hline$*$ & 8.80 & 177.60 & 106.50 & 14.0 & 77.84 & 14.20 & 83.00 & 32.00 & 7.20 & 3.42 & 11.00 & 2.70 \\
\hline$* *$ & 8.25 & 168.60 & 101.20 & NIL & 106.14 & 19.50 & 85.00 & 42.00 & 8.00 & 5.37 & 11.05 & 2.15 \\
\hline \multicolumn{13}{|c|}{ Gunji (BW) } \\
\hline$*$ & 8.10 & 335.00 & 201.00 & NIL & 84.90 & 62.04 & 92.50 & 54.00 & 15.20 & 3.90 & 27.00 & 17.50 \\
\hline$* *$ & 7.50 & 341.00 & 205.00 & NIL & 92.00 & 63.80 & 485.00 & 72.00 & 16.80 & 7.32 & 11.00 & 6.50 \\
\hline \multicolumn{13}{|c|}{ Bidi (BW) } \\
\hline$*$ & 8.90 & 461.00 & 276.00 & 6.96 & 141.50 & 58.50 & 97.00 & 82.00 & 16.00 & 10.25 & 22.50 & 1.95 \\
\hline$* *$ & 7.90 & 645.00 & 387.00 & NIL & 198.12 & 90.40 & 106.50 & 126.00 & 24.80 & 15.60 & 22.50 & 4.50 \\
\hline \multicolumn{13}{|c|}{ Parishwad (BW) } \\
\hline$*$ & 8.50 & 351.00 & 210.00 & 6.96 & 155.67 & 33.68 & 36.50 & 72.00 & 18.40 & 6.34 & 20.00 & 2.30 \\
\hline$* *$ & 7.30 & 341.00 & 205.00 & NIL & 169.82 & 37.22 & 52.00 & 78.00 & 20.80 & 6.34 & 69.00 & 8.50 \\
\hline \multicolumn{13}{|c|}{ Dastikop (BW) } \\
\hline$*$ & 8.30 & 859.00 & 515.00 & NIL & 283.04 & 108.1 & 83.00 & 190.00 & 40.80 & 21.47 & 36.50 & 2.70 \\
\hline$* *$ & 6.90 & 1198.0 & 719.00 & NIL & 325.50 & 186.1 & 90.00 & 268.00 & 52.80 & 33.18 & 203.0 & 6.10 \\
\hline \multicolumn{13}{|c|}{ Dastikop (BW) } \\
\hline$*$ & 8.50 & 1068.0 & 641.00 & 14.0 & 120.30 & 226.9 & 106.50 & 218.00 & 27.20 & 36.60 & 66.50 & 6.10 \\
\hline$* *$ & 6.70 & 1448.0 & 869.00 & NIL & 389.20 & 216.3 & 106.50 & 312.00 & 68.80 & 34.16 & 110.0 & 9.00 \\
\hline \multicolumn{13}{|c|}{ Holehosur (BW) } \\
\hline$*$ & 7.65 & 3510.0 & 2100.0 & NIL & 367.95 & 758.6 & 260.00 & 780.00 & 184.0 & 78.10 & 184.0 & 2.00 \\
\hline$* *$ & 7.00 & 3800.0 & 2280.0 & NIL & 460.00 & 753.3 & 275.00 & 828.00 & 201.6 & 79.06 & 396.0 & 6.00 \\
\hline \multicolumn{13}{|c|}{ Bailhongal (OW) } \\
\hline * & 9.60 & 780.00 & 468.00 & 69.6 & 42.45 & 109.9 & 95.00 & 48.00 & 8.00 & 6.83 & 62.00 & 46.00 \\
\hline$* *$ & 7.50 & 1330.0 & 798.00 & NIL & 460.00 & 131.2 & 100.00 & 246.00 & 61.60 & 22.45 & 188.0 & 149.0 \\
\hline Belwadi & W) & & & & & & & & & & & \\
\hline$*$ & 7.60 & 2040.00 & 1222.00 & NIL & 495.30 & 402.36 & 65.00 & 488.00 & 97.60 & 59.54 & 119.00 & 84.00 \\
\hline$* *$ & 7.10 & 2450.0 & 1472.0 & NIL & 707.60 & 432.5 & 40.00 & 564.00 & 126.4 & 60.50 & 284.0 & 146.0 \\
\hline Ugargol & W) & & & & & & & & & & & \\
\hline$*$ & 9.70 & 342.00 & 205.00 & 41.8 & 28.30 & 37.22 & 71.00 & 48.00 & 8.00 & 6.83 & 20.00 & 40.00 \\
\hline$* *$ & 7.60 & 616.00 & 369.00 & NIL & 162.75 & 69.12 & 83.00 & 98.00 & 30.40 & 5.37 & 108.0 & 168.0 \\
\hline Ugargol & W) & & & & & & & & & & & \\
\hline * & 9.10 & 1037.0 & 622.00 & 69.6 & 35.38 & 134.7 & 95.00 & 50.00 & 8.00 & 7.32 & 67.50 & 189.0 \\
\hline$* *$ & 7.60 & 1892.0 & 1135.0 & 13.9 & 353.80 & 237.5 & 295.00 & 166.00 & 44.80 & 13.17 & 40.00 & 120.0 \\
\hline
\end{tabular}


Table 1. (Continued).

\begin{tabular}{|c|c|c|c|c|c|c|c|c|c|c|c|c|}
\hline Stations & $\mathrm{pH}$ & $\begin{array}{c}\mathrm{EC} \\
\mu \mathrm{mhos} / \\
\mathrm{cm}\end{array}$ & TDS & $\mathrm{CO}_{3}$ & $\mathrm{HCO}_{3}$ & $\mathrm{Cl}$ & $\mathrm{SO}_{4}$ & $\begin{array}{l}\text { Hardness } \\
\text { as } \mathrm{CaCO}_{3}\end{array}$ & $\mathrm{Ca}$ & $\mathrm{Mg}$ & $\mathrm{Na}$ & $\mathrm{K}$ \\
\hline \multicolumn{13}{|c|}{ Ugargol (BW) } \\
\hline * & 7.90 & 2620.0 & 1570.0 & NIL & 438.70 & 290.7 & 415.00 & 218.00 & 60.80 & 16.10 & 45.00 & 180.0 \\
\hline ** & 7.00 & 2490.0 & 1792.0 & 6.96 & 396.25 & 358.0 & 415.00 & 274.00 & 55.20 & 33.20 & 60.00 & 195.0 \\
\hline \multicolumn{13}{|c|}{ Tegur (BW) } \\
\hline * & 8.75 & 853.00 & 512.00 & 20.9 & 240.58 & 134.7 & 59.00 & 116.00 & 22.40 & 14.64 & 96.00 & 1.00 \\
\hline \multicolumn{13}{|c|}{ Desur (OW) } \\
\hline & 7.80 & 2830.0 & 1701.0 & NIL & 106.14 & 666.5 & 415.00 & 500.00 & 136.0 & 39.04 & 200.0 & 236.0 \\
\hline$* *$ & 8.20 & 2960.0 & 1774.0 & NIL & 764.20 & 483.9 & 405.00 & 440.00 & 118.4 & 35.14 & 86.00 & 168.0 \\
\hline
\end{tabular}

trend in the area. Electrical conductivity was found to be highly correlated with $\mathrm{Na}(r=0.88), \mathrm{Cl}$ $(r=0.96)$ and also with sulphate $(r=0.71)$. The soluble carbonates and bicarbonates in the water samples analyzed varied from 1.04 to $8.1 \mathrm{me} \mathrm{L}^{-1}$ during pre-monsoon and 0.58 to $12.53 \mathrm{me} \mathrm{L}^{-1}$ during post-monsoon. The concentration of carbonate and bicarbonate is important because these affect the precipitation of calcium and thereby result in excessive saturation in soil. The RSC of waters indicate that about $71 \%$ samples had RSC between $2.5 \mathrm{me} \mathrm{L}^{-1}$ and $5 \mathrm{me} \mathrm{L}^{-1}$. The results indicated that the continuous and indiscriminate use of these ground waters is expected to build up excessive sodium in soil solution and exchange complex and will also clog the soil pores which may lead to drainage problem (Sood et al 1998). Soluble sodium is the dominant cation varying in concentration from 0.39 to $17.5 \mathrm{me} \mathrm{L}^{-1}$ in these waters. However, the SAR values of all samples are less than 10. It is observed that waters of high electrical conductivity values are predominant with sodium and chloride ions. This is evident at places like Holehosur, Belawadi and Desur. Further it is observed that saline waters also have relatively more calcium, magnesium and bicarbonate ions. This is observed especially at Holehosur. Potassium and carbonate ions, if present, are mostly confined up to a range of $5 \%$ of the total salt concentration. It is rather difficult to draw a general conclusion on the ionic composition of the water in relation to geographical conditions. In general, waters in areas of high rainfall, i.e., above $1000 \mathrm{~mm}$ per annum and with good drainage are of good quality. It is clear from the present study that, in the upstream where there is more rainfall (above $1000 \mathrm{~mm}$ to $3000 \mathrm{~mm}$ ) the quality of water is good whereas in the downstream area, various water quality parameters exceed the acceptable limits.

The distribution of anions and cations with total ion concentration, indicate that bicarbonates and sulphate ions are the dominating anions in the upstream, whereas towards downstream, concentration of chloride increases over bicarbonates indicating salinity problems in black soil (vertisol). Similarly among cations calcium and magnesium are the predominant ones. It is also observed that potassium shows a significant increase in its concentration at Belawadi and Ugargol. This is attributed to rock types and clay minerals rich in potassium.

In the downstream of Malaprabha sub-basin (from M. K. Hubli up to dam site) it is expected that, the most important exchange reactions involved are the removal of $\mathrm{Ca}^{2+}$ and $\mathrm{Mg}^{2+}$ out of water and to replace them with $\mathrm{Na}^{+}$. The main requirement for this process is a large reservoir of exchangeable $\mathrm{Na}^{+}$, which is most often provided by clay minerals deposited (mostly montmorillonite and smectite group). This is evident in the present study as $\mathrm{HCO}_{3}^{-}$and $\mathrm{Na}^{+}$are the ions, which indicate the presence of ion-exchanged waters.

Sodium Adsorption Ratios (SAR) of all the samples in the study area can be grouped under low-sodium hazard zone; however, the hydraulic conductivity varies considerably from low to very high. Further, the ground water samples collected from deep black soil areas showed a shift towards medium hazard zone due to continuous use of poor quality ground water. This indicates the future trend of soil and ground water salinization in these areas and therefore proper measures should be taken to control the possible impacts.

\subsection{Simulation of soil moisture movement}

The model was calibrated by using soil moisture profiles available for the Malaprabha subbasin (Purandara et al 2000). In the present study, the moisture observed during the study period was compared with the simulated profile for both upstream and downstream parts of the study area (figure $3 \mathrm{a}$ and $\mathrm{b}$ ). The profiles showed a reasonable match between the two with exception at few 

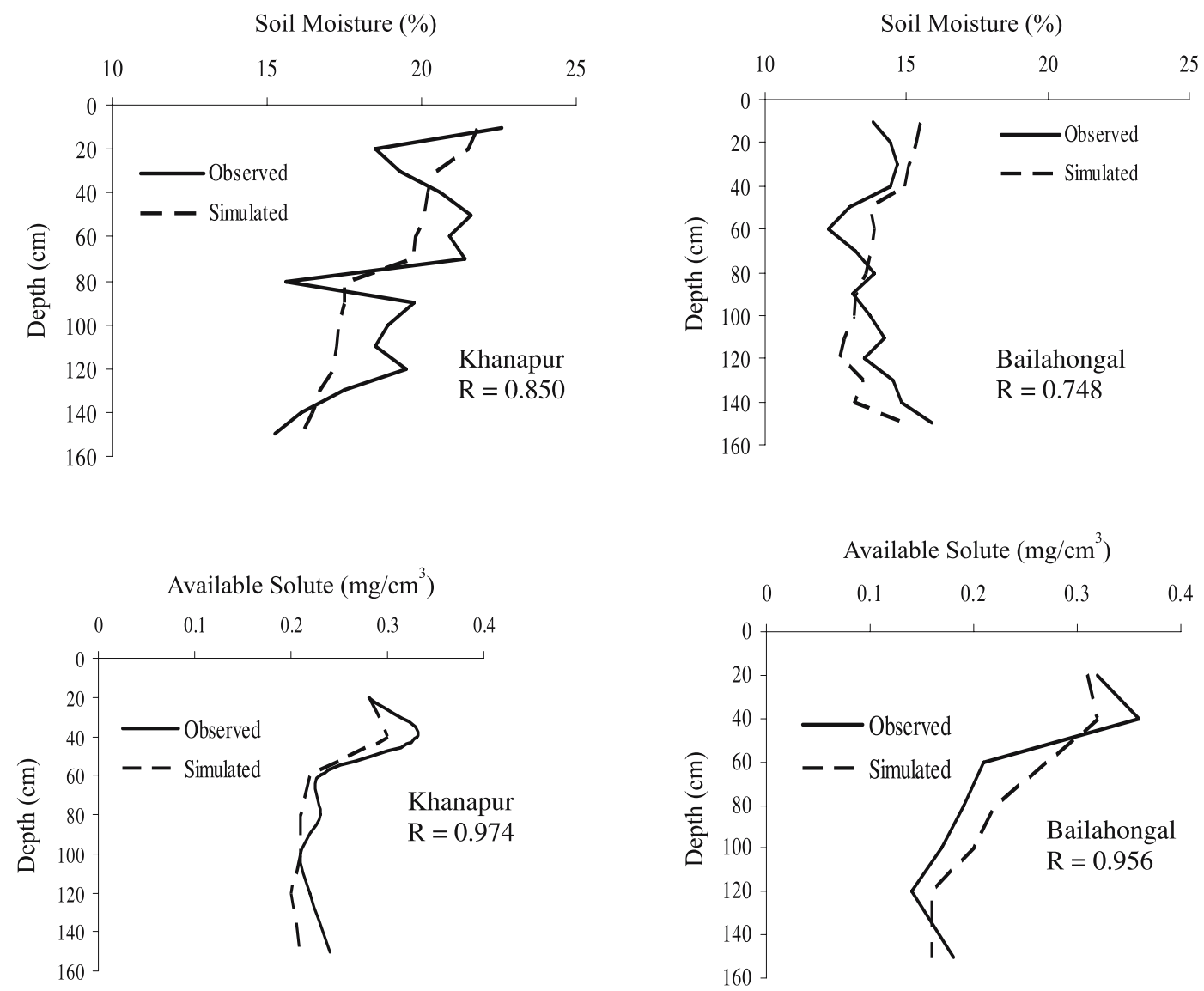

Figure 3. Comparison of observed and simulated soil moisture profiles: (a) Khanapur and (b) Bailahongal; and solute profiles: (c) Khanapur and (d) Bailahongal in Malaprabha sub-basin.

depths. The major reason for such a behaviour could be due to the limitation of data.

In the case of solute profiles (figure $3 \mathrm{c}$ and d), both observed and simulated profiles follow a similar trend of downward movement. The results indicate that in the black soil (vertisol) area, due to the very low permeability, the ions move very slowly and remain mostly in the unsaturated zone leading to the water quality problems, particularly in open wells. However, in the areas covered by red loamy soils (alfisols), due to the presence of highly porous rocks and better flow conditions, ions will be in continuous movement and get diluted without affecting the water quality. In the case of black soils (vertisols), the concentrations observed at various depths show that mostly salts are accumulated in topsoil layers due to low permeability and less rainfall. During the leaching of salts, the soil particles adsorb sodium thus making soil sodic. Further, during the rainy season, there will be an increase in water level due to which the salts deposited pass on to ground water. After the rainfall soil profile dries and the salts are stored in the sub-soil layers. Apart from this in cultivated lands, plants absorb only part of each of the nutrients present in soluble forms in soils. As the concentration of the nutrients in the soil water increases, it results in greater total nutrient absorption and greater crop yields. If fertilizers are added to supplement the supplies of particular nutrients that are deficient in soils, greater residues of the nutrients remain in the soils. Part of the excess may be lost to the groundwater if it remains in solution. Most of the chemical ions added in fertilizers are retained to some degree by soils as a result of chemical interactions, and this reduces their potential for loss to groundwater. As a consequence of such a process both soil and water get contaminated. This could be the reason for accumulation of salts in the downstream area as reported by Varadarajan (2000). The present observation also indicated that there is an accumulation of salts in the top layers of black soil (vertisol), which will ultimately lead to soil and water contamination.

\section{Conclusion}

Ground water quality and solute transport investigations have revealed that there is deterioration 
in chemical quality of both soil and water at various locations of Malaprabha sub-basin, particularly in the downstream region. The cause for deterioration of chemical quality is attributed to the unstable equilibrium between various ions such as carbonate, silicate and alumino-silicate minerals. These constituents will continue to dissolve in the saturated zone. The source of cations and anions may vary from place to place. However, the higher concentration of bicarbonates is attributed to the release of carbon dioxide by plant roots and the decomposing organic matter present in soils. The weathering of primary minerals can be described as a breakdown of silicate with the release of cations which will appear as bicarbonates.

Soil salinity and groundwater quality deterioration also depend on the climatic conditions. They increase during the summer and are considerably reduced during the monsoon due to dilution by rainwater. In the downstream area, rainfall is significantly less than in the upstream area and the climate varies from sub-humid to semi-arid, due to which there is a considerable change in ground water quality and soil salinity. Further, the variation in salinity and its ionic composition depend upon the depth of water table, infiltration capacity of the soil and the rainfall characteristics of the area concerned. The quality of groundwater in many regions shows wide variations with depth of the aquifer. The depth at which good quality water occurs varies from place to place and even within the same area at a distance of few meters. The geology of the study area shows that the basin area is covered by intertrappean clays. Under suitable conditions clay minerals (present in intertrappean beds) may release exchangeable sodium ions resulting in higher concentration of sodium. This could be the major reason for the evolution of sodium bicarbonate type of water in the Malaprabha sub-basin.

The study revealed the fact that there are soil and water salinization problems in the study area particularly in black soils. One of the major reasons as observed by the authors during the investigation is that non-utilization of the available ground water due to which the salinization problem worsens further. Therefore, it is important to pump out the water regularly and conjunctive use practice of surface- and ground-water should be adopted in such areas where the soils are affected by soil salinity. Secondly, rainwater harvesting structures and sub-surface drainage should be constructed at appropriate locations. Apart from this, certain salt tolerant crops should be grown which have already given some good results in certain areas, to reduce the intensity of salinization in the study area.

\section{Acknowledgements}

Authors are highly grateful to Dr K D Sharma, Director and Dr V K Choubey, Sc 'F', NIH, Roorkee for their encouragement in preparing the technical paper. Authors are also grateful to Karnataka Statistical Department and Karnataka Irrigation Department for providing the necessary data required for the study.

\section{References}

APHA 1985 Standard methods for the examination of water and wastewater, American Public Health Association, New York.

Bhaskar B P and Nagaraju S S 1998 Characterization of some salt affected soils occurring in the Chitravathi River basin of Andhra Pradesh; J. Indian Soc. Soil Sci. 46(3) 416-421.

Black C A 1965 Methods of analysis Part II - chemical and biological properties; Agronomy Monograph No. 9, American Society of Agronomy Inc., Madison, Wisconsin, USA.

Campbell G S 1985 "Soil Physics with BASIC"; Elsevier, NewYork, U.S.A.

De Rooij G H and Stagnitti F 2000 Spatial variability of solute leaching: Experimental validation of a quantitative parameterization; Soil Sci. Soc. Am. J. 64(2) 499-504.

Evans L and Stagnitti F 1996 Nutrient transport through basaltic agricultural soils near Australian and New Zealand National Soils Conference: Soil Science - Raising the profile, 2, Oral papers, University of Melbourne.

Jain C K, Bhatia K K S, Kumar C P and Purandara B K 2001 Irrigation water quality in Malaprabha Sub-basin, Karnataka; Ind. J. Env. Protection 21(4) 348-354.

Kumar C P and Shilpa S R 2002 Modeling of Solute Transport in Agricultural Fields using SWIM; J. Hydrol. 25(2\&3) 21-32.

Perroux K M and White I 1988 Designs for Disc Permeameters; Soil Sci. Soc. Am. J. 52 1205-1215.

Purandara B K, Venkatesh B and Varadarajan N 2000 Estimation of Groundwater Recharge under various Forest Cover, NIH technical report (unpublished).

Rajamohan N and Elango L 2001 Modelling the movement of chloride and Nitrogen in the unsaturated zone; Int UNESCO-IHP Seminar on "Modelling in Hydrogeology" held at Anna University, Chennai, India.

Rawat J S, Purandara B K and Chandrakumar S 1993 Infiltration Studies in the Malaprabha and Ghataprabha Catchment; National Institute of Hydrology, Roorkee, Case Study Report No. 105/1992-1993.

Reynolds W D and Elrick B E 1985 Measurement of field saturated hydraulic conductivity, sorptivity and the conductivity - pressure head relationship using the Guelph Permeameter; Proceedings, National Water Well Association Conference on 'Characterization and monitoring of the vadose (unsaturated) zone', Denver, Colorado.

Ross P J and Bristow K L 1990 Simulating water movement in layered and gradational soils Kirchoff transform; Soil Sci. Am. J. 54 1519-1524.

Sood A, Verma V K, Abraham T, Sharma P K and Brar J S 1998 Assessment and Management of Underground Water Quality in Talwandi Sabo Tehsil of Bathinda district (Punjab); J. Indian Soc. Soil Sci. 46(3) 412-426. 
Srivastava R and Brusseau M L 1996 Non-ideal transport of reactive solutes in heterogeneous porous media: 1. Numerical model development and moments analysis; Journal of Contaminant Hydrology 24(2) 117-143.

Stagnitti F and Li L 1999 A mathematical model for estimating the extent of solute and water-flux heterogeneity in multiple sample percolation experiments; J. Hydrol. 215(1-4) 59-69.

Stagnitti F and Li L 2001 Modelling solute transport in structured soils: Performance evaluation of the ADR and TRM models; Mathematical and Computer Modelling 34(3-4) 433-440.

Valocchi A J 1985 Validity of the local equilibrium assumption for modeling sorbing solute transport through homogeneous soils; Water Resour. Res. 21(6) 808-820.

Varadarajan N 2000 Groundwater Quality Evaluation and Modelling; M.E Thesis, Karnataka University, Dharwad, India.

Verburg Kirsten, Ross P J and Bristow K L 1996 SWIMv2.1 User Manual, Divisional report No. 130. CSIRO, Australia.

Wooding R A 1968 Steady infiltration from a shallow circular pond; Water Resour. Res. 4 1259-1273.

Xu L and Brusseau M L 1996 Semianalytical solution for solute transport in porous media with multiple spatially variable reaction processes; Water Resour. Res. 32(7) 1985-1991.

MS received 9 August 2007; revised 9 April 2008; accepted 16 April 2008 